\title{
Absorption, excretion and metabolite profiling of methyl-, glucuronyl-, glucosyl- and sulpho-conjugates of quercetin in human plasma and urine after ingestion of onions
}

\author{
William Mullen ${ }^{1}$, Christine A. Edwards ${ }^{2}$ and Alan Crozier ${ }^{1 *}$ \\ ${ }^{1}$ Plant Products and Human Nutrition Group, Graham Kerr Building, Division of Biochemistry and Molecular Biology, Institute of \\ Biomedical and Life Sciences, University of Glasgow, Glasgow G12 8QQ, UK \\ ${ }^{2}$ Human Nutrition Section, University of Glasgow Division of Developmental Medicine, Yorkhill Hospital, Glasgow G3 8SJ, UK
}

(Received 19 September 2005 - Revised 13 January 2006 - Accepted 21 February 2006)

\begin{abstract}
It is essential to have a thorough knowledge of the bioavailability and metabolism of dietary flavonols to understand their role in disease prevention. Lightly fried onions containing $275 \mu \mathrm{mol}$ flavonols, principally quercetin- $4^{\prime}$-glucoside and quercetin-3,4'-diglucoside, were fed to healthy human volunteers and plasma and urine were collected over a $24 \mathrm{~h}$ period. Samples were analysed by HPLC with diode array and tandem mass spectrometric detection. Five flavonol metabolites, quercetin-3'-sulphate, quercetin-3-glucuronide, isorhamnetin-3-glucuronide, a quercetin diglucuronide and a quercetin glucuronide sulphate, were detected in plasma in quantifiable amounts with trace quantities of six additional quercetin metabolites. Sub-micromolar peak plasma concentrations $\left(C_{\max }\right)$ of quercetin-3'-sulphate, quercetin-3-glucuronide, isorhamnetin-3-glucuronide and quercetin diglucuronide were observed $0.6-0.8 \mathrm{~h}$ after ingestion. In contrast, the $C_{\max }$ of quercetin glucuronide sulphate was $2.5 \mathrm{~h}$. The elimination half-lives $\left(t_{1 / 2}\right)$ of quercetin- $3^{\prime}$-sulphate, quercetin-3-glucuronide and quercetin diglucuronide were $1.71,2.33$ and $1.76 \mathrm{~h}$ respectively, while the $t_{1 / 2}$ of isorhamnetin-3-glucuronide was $5.34 \mathrm{~h}$ and that of quercetin glucuronide sulphate was $4.54 \mathrm{~h}$. The profile of metabolites excreted in urine was markedly different to that of plasma with many of the major urinary components, including quercetin- $3^{\prime}$-glucuronide, two quercetin glucoside sulphates and a methylquercetin diglucuronide, absent or present in only trace amounts in the bloodstream indicative of substantial phase II metabolism. Total urinary excretion of quercetin metabolites was $12.9 \mu \mathrm{mol}$, corresponding to $4.7 \%$ of intake. If these samples had been subjected to hydrolysis, as in many previous studies, only quercetin and isorhamnetin would have been detected and quantified. The bioactivity of these metabolites should be considered.
\end{abstract}

Flavonols: Quercetin glucosides: Absorption: Metabolism: Excretion: Man: HPLC-MS ${ }^{2}$

Flavonols are polyphenolic C6-C3-C6 compounds which, along with other flavonoids and phenolics, occur widely in plants and plant-derived foods and beverages (Crozier et al. 2006). They have several potential nutritional and health-promoting roles in the human body but there is still much to be learnt about their bioavailability and, in particular, which metabolites appear in plasma and in what amounts. This information is essential to understanding the potential role of these compounds in reducing CHD and cancer as it is likely that the metabolites do not have the same bioactivity as the parent compounds. To gain a full picture of the absorption and metabolism of flavonols it is essential to be able to detect and quantify all the major metabolites in plasma and urine and this requires the use of appropriate analytical methodology such as HPLC with tandem MS $\left(\mathrm{MS}^{2}\right)$.

Quercetin is the major flavonol in many foods including onions which consistently contain high levels of flavonols (Crozier et al. 1998) in the form of quercetin-3,4'-diglucoside (I in Fig. 1), quercetin-4'-glucoside (II in Fig. 1), and smaller amounts of other conjugates including isorhamnetin-4'-glucoside (III in Fig. 1) (Tsushida \& Suzuki, 1995). It is now believed that absorption of quercetin glucosides from the gastrointestinal tract involves deglycosylation by luminal lactase phloridzin hydrolase and/or cleavage within the enterocyte by cytosolic $\beta$-glucosidase (Day et al. 2003). This is followed by metabolism of the aglycone which leads to the appearance of quercetin sulphate and glucuronide conjugates in the circulatory system (Day \& Williamson, 2003). These metabolites are not available from commercial sources, which precludes their direct analysis. Thus, in initial studies on quercetin derivatives accumulating in plasma and urine, samples were treated with either acid or glucuronidase/sulphatase enzymes to release the parent aglycone prior to quantitative analysis by HPLC (Hollman et al. 1996, 1997; Aziz et al. 1998; Moon et al. 2000; Graefe et al. 2001).

More recently, the use of HPLC-MS has facilitated the analysis of flavonol metabolites without recourse to acid or enzyme treatment. An investigation using HPLC-MS ${ }^{2}$ in

Abbreviations: $C_{\max }$, maximum post-ingestion plasma concentration of quercetin metabolites; $\mathrm{MS}^{2}$, tandem MS; PDA, photodiode array; $t_{\text {max }}$, time to reach $C_{\text {max }}$; $t_{\mathrm{R}}$, retention time; $t_{1 / 2}$, the elimination half-life of the metabolites.

* Corresponding author: Professor Alan Crozier, fax +44 (0)141 330 5364, email a.crozier@bio.gla.ac.uk 


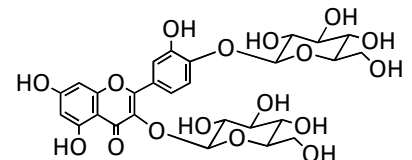

Quercetin-3,4'-O-diglucoside (I)

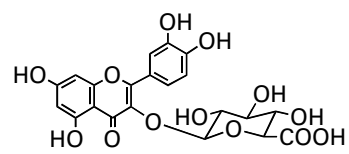

Quercetin-3-glucuronide (IV)

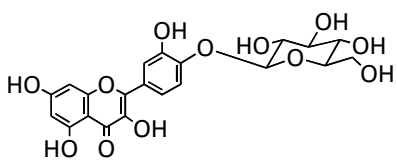

Quercetin-4'-O-glucoside (II)

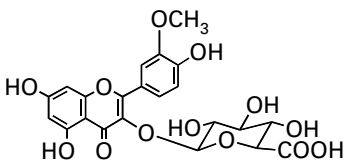

Isorhamnetin-3-glucuronide (V)

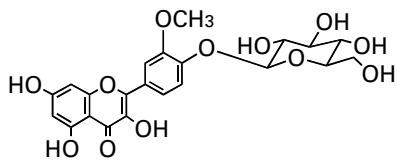

Isorhamnetin-4'-O-glucoside (III)<smiles></smiles>

Quercetin-3'-sulphate (VI)

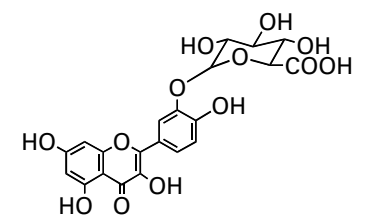

Quercetin-3'-O-glucuronide (VII)

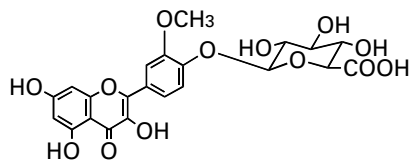

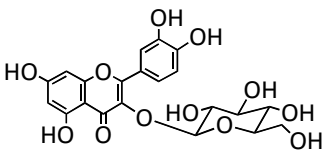

Isorhamnetin-4'-O-glucuronide (VIII) Quercetin-3-glucoside (IX)

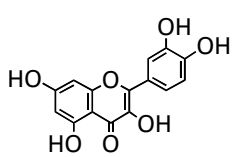

Quercetin (XI)

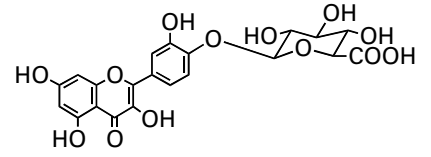

Quercetin-4'-O-glucuronide (XII)

Fig. 1. Structures of flavonol glucosides and their metabolites.

the selected reaction monitoring mode detected five quercetin glucuronides in human plasma collected $1 \mathrm{~h}$ after ingestion of an $800 \mathrm{~g}$ onion supplement (Wittig et al. 2001). A further study in which plasma, collected $1.5 \mathrm{~h}$ post-ingestion of $200 \mathrm{~g}$ fried onions, was analysed by HPLC identified in total twelve putative quercetin metabolite peaks (Day et al. 2001). Identifications were based on chromatographic retention times $\left(t_{\mathrm{R}}\right)$ of absorbance peaks at $365 \mathrm{~nm}$ and enzyme hydrolysis data. Additional confirmation of metabolite identities was by MS analysis in selected ion monitoring mode which identified three of these metabolites as quercetin-3-glucuronide (IV in Fig. 1), isorhamnetin-3-glucuronide ( $\mathrm{V}$ in Fig. 1) and quercetin- $3^{\prime}$-sulphate (VI in Fig. 1) (Day et al. 2001). Subsequently, Mullen et al. (2004) fed $270 \mathrm{~g}$ lightly fried onions to human subjects and, using HPLC with photodiode array (PDA) and $\mathrm{MS}^{2}$ detection, were able to identify twenty-three quercetin-based compounds in plasma and urine collected 1 and $0-4 \mathrm{~h}$ respectively, after ingestion. Here we report an extension of the earlier study in which plasma and urinary metabolites from six volunteers were analysed quantitatively in samples collected at a series of timepoints over a $24 \mathrm{~h}$ period after supplementation.

\section{Methods}

\section{Study design}

Six volunteers (four males and two females), who were healthy, non-smokers and not on any medication, participated in the present study and gave their written consent. They were aged between 23 and 45 years and had a mean BMI of 23.7 (SE 1.2) (range 20.9-27.6). Subjects were required to follow a low flavonoid diet for $2 \mathrm{~d}$ and to fast overnight prior to supplementation. This diet excluded most fruits, vegetables and beverages including tea, coffee, fruit juices and wine. On the morning of the study, red onions (Allium cepa) were skinned, chopped into small slices, and fried for $4 \mathrm{~min}$ in margarine. Aliquots of the fried onions were taken for qualitative and quantitative analysis of their flavonol content.

All subjects consumed $270 \mathrm{~g}$ fried onions. Venous blood samples were taken before $(0 \mathrm{~h})$ and $0.5,1,2,3,6$ and $24 \mathrm{~h}$ post-ingestion. Blood $(12 \mathrm{ml})$ was collected in heparinised tubes at each time-point and immediately centrifuged at $4000 \mathrm{~g}$ for $10 \mathrm{~min}$ at $4^{\circ} \mathrm{C}$. The plasma was separated from the erythrocytes and $500 \mu \mathrm{l}$ aliquots were acidified to $\mathrm{pH} 3$ with $15 \mu \mathrm{l} 50 \%$ aqueous formic acid and $50 \mu \mathrm{l}$ ascorbic acid $(10 \mathrm{~mm})$ added to prevent oxidation. The plasma samples were then stored at $-80^{\circ} \mathrm{C}$ prior to analysis. Urine was collected before and over $0-4,4-8$ and $8-24 \mathrm{~h}$ periods after the consumption of the fried onion supplement. The volume of each sample was recorded prior to acidification to $\mathrm{pH} 3.0$ and the storage of aliquots at $-80^{\circ} \mathrm{C}$. The study protocol was approved by the Glasgow Royal Infirmary Local Research Ethics Committee.

\section{Materials}

Onions were purchased from a local supermarket (Sainsbury's, Glasgow, UK). HPLC-grade methanol and acetonitrile were obtained from Rathburn Chemicals (Walkerburn, UK). 
Formic acid was purchased from Riedel-DeHaen (Seeize, Germany) and acetic acid from BDH (Poole, UK). L-(+)Ascorbic acid, quercetin and isorhamnetin-3-glucoside were purchased from Extrasynthese (Genay, France). AASC Ltd (Southampton, UK) supplied quercetin-3,4'-diglucoside, quercetin- $4^{\prime}$-glucoside, quercetin-3-glucoside and isorhamnetin- $4^{\prime}$ glucoside.

$\left[2-{ }^{14} \mathrm{C}\right]$ Quercetin- $4{ }^{\prime}-O-\beta-\mathrm{D}-$ glucoside was synthesised in four steps from barium $\left[{ }^{14} \mathrm{C}\right]$ carbonate (specific activity $3.75 \mathrm{mCi} / \mathrm{mmol}$ ) by a method previously reported for the synthesis of $\left[2-{ }^{13} \mathrm{C}\right]$ quercetin- $4^{\prime}-O-\beta$-D-glucoside (Caldwell et al. 2000) except that the intermediate ester was not purified by filtration through alumina. The compound was pure by ${ }^{1} \mathrm{H}$ NMR spectroscopy and only one radioactive peak was detected by HPLC-radio counting.

Quercetin-3-glucuronide was extracted from French beans (Phaseolus vulgaris) and purified by partitioning against ethyl acetate and fractionation using preparative reversedphase HPLC. Quercetin- $3^{\prime}$-glucuronide, quercetin- $4^{\prime}$-glucuronide, quercetin-3'-sulphate and isorhamnetin-3-glucuronide were kindly donated by Dr Paul Needs and Dr Paul Kroon (Institute of Food Research, Norwich, UK).

\section{Extraction of onions}

Aliquots of fried onions were taken for quantitative analysis of their flavonol content. Prior to the extraction, they were frozen in liquid nitrogen, lyophilised and powdered. Triplicate samples were extracted as follows: $35 \mathrm{mg}$ dry powder were homogenised in $3 \mathrm{ml} 70 \%$ methanol in water for $1 \mathrm{~min}$ using an Ultra-Turrax T 25 (IKA ${ }^{\mathrm{R}}$-Werke, Staufen, Germany). During the homogenisation, the samples were kept on ice. The mixture was then centrifuged at $3000 \mathrm{~g}$ at $4^{\circ} \mathrm{C}$ for $15 \mathrm{~min}$. The supernatant was collected and the pellet further extracted and centrifuged twice. The three supernatants were combined and reduced to dryness in vacuo. The dried extract was dissolved in $300 \mu \mathrm{l}$ methanol and $1200 \mu \mathrm{l} 5 \%$ formic acid in water, before being centrifuged at $25000 \mathrm{~g}$ at $4^{\circ} \mathrm{C}$ for $10 \mathrm{~min}$. Aliquots $(20 \mu \mathrm{l})$ of the supernatant were analysed by HPLC-PDA-MS ${ }^{2}$.

\section{Extraction of plasma}

Triplicate samples of plasma were treated according to the method of Day et al. (2001). This involved adding $1.5 \mathrm{ml}$ acetonitrile to $500 \mu \mathrm{l}$ plasma. Samples were vortexed for $30 \mathrm{~s}$ every $2 \mathrm{~min}$ over a $10 \mathrm{~min}$ period, before centrifuging the mixture at $4000 \mathrm{~g}$ at $4^{\circ} \mathrm{C}$ for $10 \mathrm{~min}$. The supernatant was collected and the pellet re-extracted as described earlier but with methanol instead of acetonitrile. Experiments with $\left[{ }^{14} \mathrm{C}\right]$ quercetin- $4^{\prime}$-glucoside, querctin-3-glucuronide and quercetin- $3^{\prime}$-sulphate showed recoveries of about $75 \%$ with the initial acetonitrile extraction which increased by a further $10-12 \%$ with the second methanolic extraction. The acetonitrile and methanol supernatants were combined and reduced to dryness in vacuo. Extracts were then dissolved in $25 \mu \mathrm{l}$ methanol plus $225 \mu 11 \%$ formic acid in water and centrifuged at $25000 \mathrm{~g}$ at $4^{\circ} \mathrm{C}$ for $10 \mathrm{~min}$ prior to the analysis of $100 \mu \mathrm{l} \mathrm{ali-}$ quots of the supernatant by HPLC-PDA-MS ${ }^{2}$ on the day of extraction. $\left[2-{ }^{14} \mathrm{C}\right]$ Quercetin- $4{ }^{\prime}$-glucoside, used as an internal standard, was added to the plasma prior to extraction with acetonitrile. The level of radioactivity present in the sample prior to analysis was used to determine the extraction efficiency. Preliminary tests had shown no quercetin- $4^{\prime}$-glucoside was present in the plasma samples.

\section{Urine}

The acidified frozen urine was defrosted, methanol was added to make the solution $5 \%$ aqueous methanol, which resulted in any precipitated material being re-dissolved, and $100 \mu \mathrm{l}$ aliquots were analysed directly by HPLC-PDA-MS ${ }^{2}$ without further processing.

\section{HPLC with diode array and tandem MS detection}

Samples were analysed on a Surveyor HPLC system comprising an HPLC pump, PDA detector, scanning from 250 to $700 \mathrm{~nm}$ and an autosampler cooled to $4^{\circ} \mathrm{C}$ (Thermo Finnigan, San Jose, CA, USA). Separation was carried out using a $250 \times 4.6 \mathrm{~mm}$ i.d. $4 \mu \mathrm{m}$ Synergi Max-RP column (Phenomenex, Macclesfield, UK) eluted with a $60 \mathrm{~min}$ gradient of $5-40 \%$ acetonitrile in $1 \%$ formic acid at a flow rate of $1 \mathrm{ml} / \mathrm{min}$ and maintained at $40^{\circ} \mathrm{C}$. After passing through the flow cell of the diode array detector the column eluate was split and $0.3 \mathrm{ml} / \mathrm{min}$ was directed to a LCQ DecaXP ion trap mass spectrometer fitted with an electrospray interface (Thermo Finnigan). Analyses utilised the negative ion mode as this provided the best limit of detection for flavonols and their metabolites. Analysis was carried out using full-scan, data-dependent $\mathrm{MS}^{2}$ scanning from $\mathrm{m} / \mathrm{z} 100$ to 1000. Capillary temperature was $350^{\circ} \mathrm{C}$, sheath gas and auxiliary gas were 60 and 10 units respectively, and the source voltage was $4 \mathrm{kV}$ for negative ionisation and $1 \mathrm{kV}$ for positive ionisation.

Quercetin, quercetin-3,4'-diglucoside, quercetin-4'-glucoside, quercetin-3-glucoside, isorhamnetin- $4^{\prime}$-glucoside, quercetin-3-glucuronide and quercetin- $3^{\prime}$-sulphate were all quantified by reference to standard calibration curves at $365 \mathrm{~nm}$. Other flavonols were quantified in quercetin- $4^{\prime}$-glucoside equivalents with the exception of a partially identified quercetin sulphate that was quantified in quercetin- $3^{\prime}$-sulphate equivalents. In all instances peak identification was confirmed by HPLC retention times and $\mathrm{MS}^{2}$ fragmentation data.

\section{Pharmacokinetic analysis of plasma metabolites}

Maximum post-ingestion plasma concentration of quercetin metabolites was defined as $C_{\max }$. The time to reach maximum plasma concentration $\left(t_{\max }\right)$ was defined as the time in hours at which $C_{\max }$ was reached. The elimination half-life for the metabolites in hours was computed by using the following formula: $t_{1 / 2}=0.693 / K_{e}$ where $K_{e}$ is the slope of the linear regression of the $\log$ of $0-24 \mathrm{~h}$ plasma metabolite concentrations.

\section{Results}

\section{Analysis of fried onions}

Gradient reverse-phase HPLC with absorbance detection and full-scan data-dependent $\mathrm{MS}^{2}$ was used to identify and quantify the flavonol content of fried onion meals. Absorbance at 
$365 \mathrm{~nm}$ and negative ionisation $\mathrm{MS}^{2}$ were used for flavonol analysis. The total amount of flavonols in the $270 \mathrm{~g}$ onion meal was 275 (SE 8.8) $\mu$ mol. In keeping with the data of Tsushida \& Suzuki (1995), the major components were quercetin-3,4'-diglucoside (I; 107 (SE 1.4) $\mu \mathrm{mol}$ ), quercetin-4'-glucoside (II; 143 (SE 12) $\mu \mathrm{mol}$ ) and isorhamnetin-4'-glucoside (III; 11 (SE 1.4)) $\mu \mathrm{mol}$ ) which accounted for $95 \%$ of the 275 (SE 8.8) $\mu \mathrm{mol}$ flavonol intake.

\section{Qualitative analysis of plasma and urine}

Plasma and urine samples were analysed by HPLC with PDA and $\mathrm{MS}^{2}$ detection. Flavonol metabolites were present in plasma and urine, corresponding to about $4 \%$ of the intake, with a total of twenty-three quercetin-based compounds being detected. Typical HPLC traces obtained with absorbance at $365 \mathrm{~nm}$ are illustrated in Fig. 2 and the identifications based on $\mathrm{MS}^{2}$ spectra and $t_{\mathrm{R}}$ data are summarised in Table 1. The use of HPLC-MS ${ }^{2}$ to identify these quercetin metabolites has been discussed in detail in a publication by Mullen et al. (2004).

\section{Quantitative analysis of flavonol metabolites in plasma}

Eleven quercetin metabolites were detected in plasma in quantities that facilitated either their full or partial identification as outlined in Table 1. Those present in sufficient quantities to enable pharmacokinetic profiles to be obtained were a quercetin diglucuronide (peak 9), a quercetin glucuronide sulphate (peak 14), quercetin-3-glucuronide (IV), isorhamnetin-3-glucuronide (V) and quercetin-3'-sulphate (VI). Quercetin-3'-glucuronide (VII) and isorhamnetin- $4^{\prime}$-glucuronide (VIII) was present in the plasma of all the human subjects in low, nonquantifiable, amounts while other flavonol derivatives, quercetin-3,4'-diglucoside, quercetin-3-glucoside (IX), isorhamnetin-3-glucoside (X) and the aglycone quercetin (XI), were detected, albeit in very small quantities, only in the plasma of volunteer 6 (Table 1).

The 0-6h pharmacokinetic profiles of the five major plasma flavonol metabolites are illustrated in Fig. 3. No quercetin metabolites were present in plasma samples collected at either prior $(0 \mathrm{~h})$ or $24 \mathrm{~h}$ after supplementation. This was confirmed using the enhanced sensitivity and selectivity of $\mathrm{MS}^{2}$ in the selected reaction monitoring mode. Pharmacokinetic analyses of the $0-24 \mathrm{~h}$ data-points are summarised in Table 3. The two main metabolites which accumulated in plasma were quercetin- $3^{\prime}$-sulphate and quercetin-3-glucuronide. These compounds had a $C_{\max }$ of 665 (SE 82) and 351 (SE 27) nM respectively. In both instances $t_{\max }$ was less than $1 \mathrm{~h}$ after the ingestion of the onion supplement (Table 2). A quercetin diglucuronide (peak 9) had a similar $t_{\max }(0.80(\mathrm{SE} 0.12) \mathrm{h})$ but a lower $C_{\max }(62$ (SE 12) nM) than the two main metabolites. The levels of all three metabolites declined after reaching $C_{\max }$ (Fig. 4) and they had a similar $t_{1 / 2}$ with values of $1.71-$ $2.33 \mathrm{~h}$ (Table 3 ). The pharmacokinetic profiles of isorhamnetin-3-glucuronide and quercetin glucuronide sulphate (peak 14) were different to those of the other metabolites

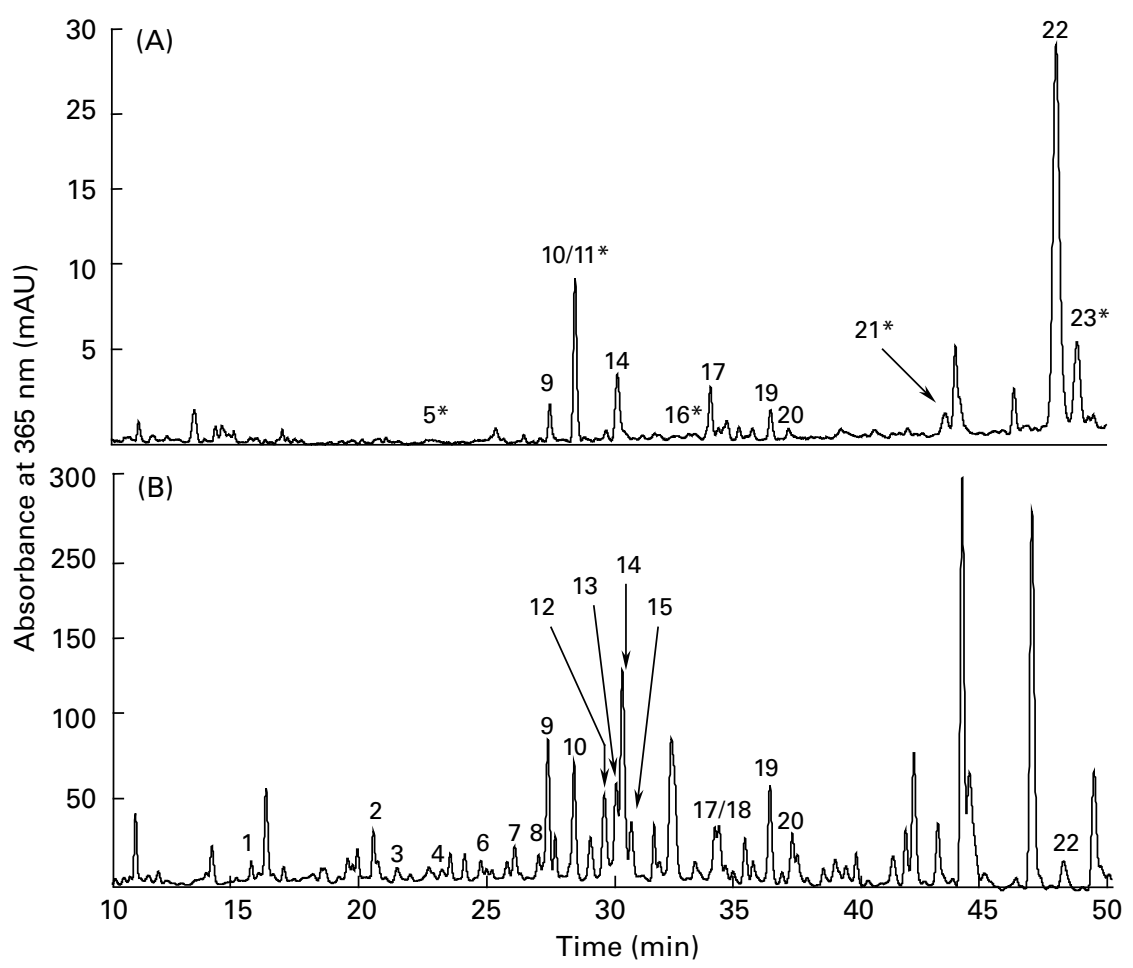

Fig. 2. Gradient reversed-phase HPLC with detection at $365 \mathrm{~nm}$ of quercetin metabolites in a plasma extract (A) and urine (B) obtained from a human subject after the consumption of $270 \mathrm{~g}$ of fried onions. Samples were analysed on a $250 \times 4.6 \mathrm{~mm}$ i.d., $4 \mu \mathrm{m}$ Synergi Max-RP column at $40^{\circ} \mathrm{C}$ and eluted at a flow rate of $1 \mathrm{ml} / \mathrm{min}$ with a $60 \mathrm{~min}$ gradient of $5-40 \%$ acetonitrile in water containing $1 \%$ formic acid. Detection was with a diode array detector operating at $365 \mathrm{~nm}$. Peaks 1-23 represent components subsequently analysed by tandem MS with an electrospray interface with negative ionisation. For identity of peaks 1-23, see Table 1. *Peaks detected in samples from only one of the six human subjects. AU, arbitrary units. 
Table 1. HPLC-tandem MS $\left(\mathrm{MS}^{2}\right)$ identification of quercetin metabolites detected in plasma and urine of six human subjects after the consumption of $270 \mathrm{~g}$ fried onions*

\begin{tabular}{|c|c|c|c|c|c|}
\hline Peak† & $\underset{(\mathrm{min}) \dagger}{t_{\mathrm{R}}}$ & Compound & $\begin{array}{l}{[\mathrm{M}-\mathrm{H}]^{-}} \\
(\mathrm{m} / \mathrm{z})\end{array}$ & $\mathrm{MS}^{2}$ fragments ions $(\mathrm{m} / \mathrm{z})$ & Location \\
\hline 1 & $15 \cdot 6$ & Quercetin diglucuronide & 653 & $477\left([\mathrm{M}-\mathrm{H}]^{-}-\mathrm{GlcUA}\right), 301\left([\mathrm{M}-\mathrm{H}]^{-}-\mathrm{GlcUA}-\mathrm{GlcUA}\right)$ & Urine \\
\hline 3 & $21 \cdot 5$ & Quercetin glucoside glucuronide & 639 & $477\left([\mathrm{M}-\mathrm{H}]^{-}-\mathrm{Glc}\right), 463\left([\mathrm{M}-\mathrm{H}]^{-}-\mathrm{GlcUA}\right), 301\left([\mathrm{M}-\mathrm{H}]^{-}-\mathrm{GlcUA}-\mathrm{Glc}\right)$ & Urine \\
\hline 4 & $22 \cdot 7$ & Methylquercetin diglucuronide & 667 & $491\left([\mathrm{M}-\mathrm{H}]^{-}-\mathrm{GlcUA}\right), 315\left([\mathrm{M}-\mathrm{H}]^{-}-\mathrm{GlcUA}-\mathrm{GlcUA}\right)$ & Urine \\
\hline 5 & $22 \cdot 8$ & Quercetin-3,4'-diglucoside $\neq$ & 625 & $463\left([\mathrm{M}-\mathrm{H}]^{-}-\mathrm{Glc}\right), 301\left([\mathrm{M}-\mathrm{H}]^{-}-\mathrm{Glc}-\mathrm{Glc}\right)$ & Plasma \\
\hline 6 & $24 \cdot 8$ & Quercetin diglucuronide & 653 & $477\left([\mathrm{M}-\mathrm{H}]^{-}-\mathrm{GlcUA}\right), 301\left([\mathrm{M}-\mathrm{H}]^{-}-\mathrm{GlcUA}-\mathrm{GlcUA}\right)$ & Urine \\
\hline 8 & $27 \cdot 0$ & Quercetin glucoside glucuronide & 639 & $477\left([\mathrm{M}-\mathrm{H}]^{-}-\mathrm{Glc}\right), 463\left([\mathrm{M}-\mathrm{H}]^{-}-\mathrm{GlcUA}\right), 301\left([\mathrm{M}-\mathrm{H}]^{-}-\mathrm{Glc}-\mathrm{GlcUA}\right)$ & Urine \\
\hline 9 & $27 \cdot 4$ & Quercetin diglucuronide & 653 & $477\left([\mathrm{M}-\mathrm{H}]^{-}-\right.$GlcUA $), 301\left([\mathrm{M}-\mathrm{H}]^{-}-\right.$GlcUA-GlcUA) & Urine, plasma \\
\hline 10 & $28 \cdot 4$ & Quercetin-3-glucuronide & 477 & $301\left([\mathrm{M}-\mathrm{H}]^{-}-\mathrm{GlcUA}\right)$ & Urine, plasma \\
\hline 11 & $28 \cdot 4$ & Quercetin-3-glucoside & 463 & $301\left([\mathrm{M}-\mathrm{H}]^{-}-\mathrm{Glc}\right)$ & Plasma \\
\hline 12 & $29 \cdot 6$ & Quercetin glucoside sulphate & 543 & $463\left([\mathrm{M}-\mathrm{H}]^{-}-\mathrm{SO}_{3}\right), 381\left([\mathrm{M}-\mathrm{H}]^{-}-\mathrm{Glc}\right), 301\left([\mathrm{M}-\mathrm{H}]^{-}-\mathrm{SO}_{3}-\mathrm{Glc}\right)$ & Urine \\
\hline 13 & $30 \cdot 1$ & Quercetin glucuronide sulphate & 557 & $477\left([\mathrm{M}-\mathrm{H}]^{-}-\mathrm{SO}_{3}\right), 381\left([\mathrm{M}-\mathrm{H}]^{-}-\mathrm{GlcUA}\right), 301\left([\mathrm{M}-\mathrm{H}]^{-}-\mathrm{SO}_{3}-\mathrm{GlcUA}\right)$ & Urine \\
\hline 14 & $30 \cdot 3$ & Quercetin glucuronide sulphate & 557 & $477\left([\mathrm{M}-\mathrm{H}]^{-}-\mathrm{SO}_{3}\right), 381\left([\mathrm{M}-\mathrm{H}]^{-}-\mathrm{GlcAU}\right), 301\left([\mathrm{M}-\mathrm{H}]^{-}-\mathrm{SO}_{3}-\mathrm{GlcUA}\right)$ & Urine, plasma \\
\hline 15 & $30 \cdot 6$ & Quercetin glucoside sulphate & 543 & $463\left([\mathrm{M}-\mathrm{H}]^{-}-\mathrm{SO}_{3}\right), 381\left([\mathrm{M}-\mathrm{H}]^{-}-\mathrm{Glc}\right), 301\left([\mathrm{M}-\mathrm{H}]^{-}-\mathrm{SO}_{3}-\mathrm{Glc}\right)$ & Urine \\
\hline 17 & $34 \cdot 1$ & Isorhamnetin-3-glucuronide & 491 & $315\left([\mathrm{M}-\mathrm{H}]^{-}-\mathrm{GlcU} A\right)$ & Urine, plasma \\
\hline 18 & 34.4 & Quercetin-4'-glucuronide & 477 & $301\left([\mathrm{M}-\mathrm{H}]^{-}-\mathrm{GI}\right.$ CUA) & Urine \\
\hline 19 & $36 \cdot 3$ & Quercetin-3'-glucuronide & 477 & $301\left([\mathrm{M}-\mathrm{H}]^{-}-\mathrm{GlcUA}\right)$ & Urine, plasma \\
\hline 20 & $37 \cdot 2$ & Isorhamnetin-4'-glucuronide & 491 & $315\left([\mathrm{M}-\mathrm{H}]^{-}-\mathrm{GlcUA}\right)$ & Urine, plasma \\
\hline 21 & $43 \cdot 2$ & Quercetin $\ddagger$ & 301 & 179,151 & Plasma \\
\hline 22 & $47 \cdot 9$ & Quercetin-3'-sulphate & 381 & $301\left([\mathrm{M}-\mathrm{H}]^{-}-\mathrm{SO}_{3}\right)$ & Urine, plasma \\
\hline 23 & $48 \cdot 3$ & Quercetin sulphate‡ & 381 & $301\left([\mathrm{M}-\mathrm{H}]^{-}-\mathrm{SO}_{3}\right)$ & Plasma \\
\hline
\end{tabular}

Glc, glucosyl unit; GIcUA, glucuronyl unit; $[\mathrm{M}-\mathrm{H}]^{-}$, negatively charged molecular ion; $t_{\mathrm{R}}$, retention time.

${ }^{*}$ For details of procedures, see p. 108.

†Peak numbers and HPLC retention times refer to HPLC traces in Fig. 2.

$\ddagger$ Compounds detected only in the plasma of one of the six human subjects.

illustrated in Fig. 3. Isorhamnetin-3-glucuronide had a $C_{\max }$ of 112 (SE 18) nM and a $t_{\max }$ of $0.60 \mathrm{~h}$ and there was a slow rate of decline after $C_{\max }$ which is reflected in a $t_{1 / 2}$ of $5.34 \mathrm{~h}$ (Table 3). The $C_{\max }$ of the quercetin glucuronide sulphate (peak 14) was 123 (SE 26) nM while its $t_{\max }$ at 2.5 (SE $0 \cdot 22) \mathrm{h}$ was delayed compared to that of the other metabolites and the $t_{1 / 2}(4.54 \mathrm{~h})$ was much slower than that observed with quercetin- 3 '-sulphate, quercetin-3-glucuronide and the quercetin diglucuronide (Table 3).

\section{Quantitative analysis of flavonol metabolite excretion in urine}

Eighteen flavonol metabolites were detected in urine samples collected $0-4,4-8$ and $8-24 \mathrm{~h}$ after the ingestion of red onions (Table 1). Six of these compounds, two quercetin diglucuronides (peaks 1 and 6), two quercetin glucoside sulphates (peaks 7 and 8), quercetin-4'-glucuronide (XII) and quercetin- $3^{\prime}$-sulphate, were present in quantities insufficient for routine quantification.

Twelve urinary metabolites were detected in amounts that facilitated quantitative analysis (Table 4). These metabolites consisted of quercetin-3-glucuronide, quercetin-3'-glucuronide a quercetin diglucuronide, a quercetin glucuronide glucoside, two quercetin glucuronide sulphates, two quercetin glucoside sulphates, isorhamnetin-3-glucuronide, isorhamnetin-4'-glucuronide and two methylquercetin diglucuronides. The main urinary metabolite present was a quercetin diglucuronide (peak 9) with 2223 (SE 417) nmol being excreted over the $24 \mathrm{~h}$ period following ingestion of the onion supplement. Substantial amounts of quercetin-3'-glucuronide (1845 (SE 193) $\mathrm{nmol}$ ), isorhamnetin-3-glucuronde (1789 (SE 27) nmol) and two quercetin glucuronide sulphates (peak 13, 1384 (SE 163) nmol; peak 14, 1229 (SE 190) nmol) were also detected.

\section{Discussion}

The results of the present study have provided, for the first time, detailed quantitative concentrations of metabolites of methyl-, glucuronyl- and sulpho-conjugates of quercetin in the plasma and urine of human subjects after ingestion of onions. The pharmacokinetics presented should allow better and more relevant studies of the bioactivity and role of dietary flavonols in disease prevention.

\section{Quantitative analysis of flavonol absorption}

The two major metabolites, quercetin- $3^{\prime}$-sulphate and quercetin-3-glucuronide, appeared in plasma within $30 \mathrm{~min}$ of the ingestion of onions, both had $t_{\max }$ values of under $1 \mathrm{~h}$ and $t_{1 / 2}$ values of 1.71 and $2.33 \mathrm{~h}$ respectively (Fig. 3; Table 3). A quercetin diglucuronide (peak 9) with a lower $C_{\max }$ and similar $t_{\max }$ and $t_{1 / 2}$ values was also detected. The pharmacokinetic profiles of isorhamnetin-3-glucuronide and a quercetin glucuronide sulphate (peak 14) were somewhat different in that both had a much longer $t_{1 / 2}$ and the glucuronide sulphate also had a much delayed $t_{\max }$. However, the total contribution of these two compounds to the overall absorption profile was minimal, having no effect on the $t_{\max }$ and only extending the $t_{1 / 2}$ to $2.61 \mathrm{~h}$. This $t_{1 / 2}$ is much shorter than in similar absorption studies carried out previously (Hollman et al. 1996, 1997; Aziz et al. 1998; Graefe et al. 2001) 


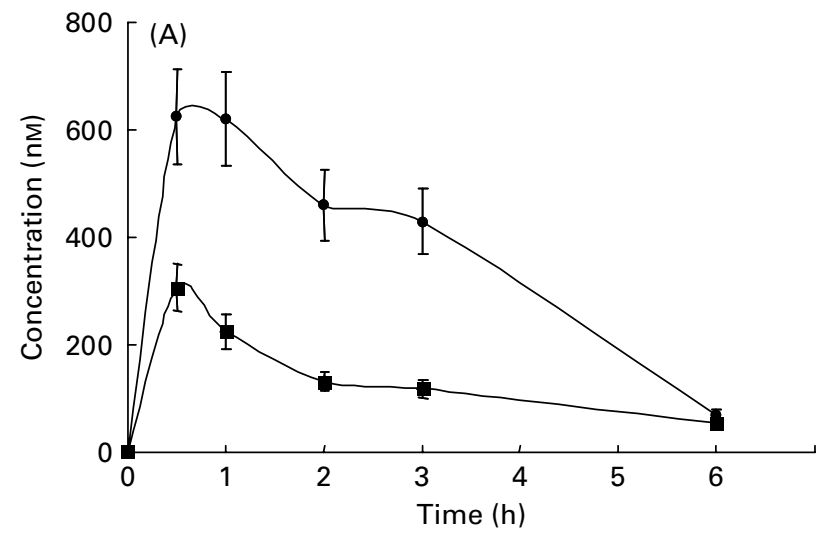

(B)

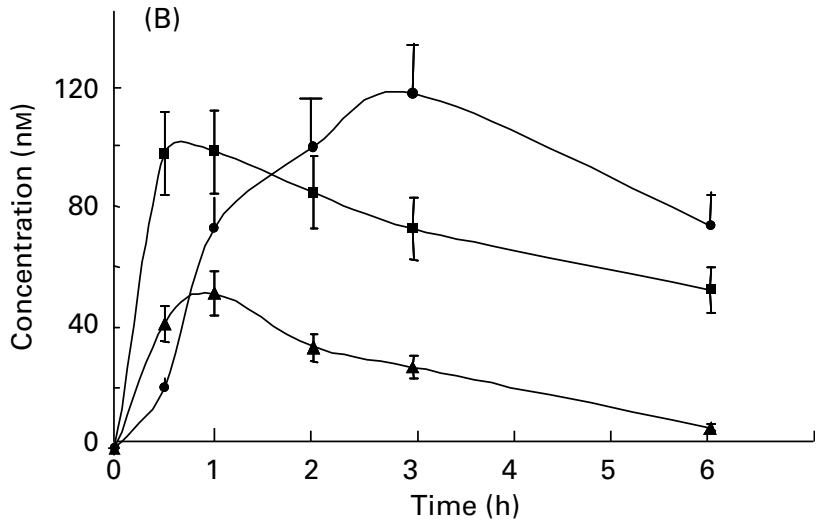

Fig. 3. (A), Concentration of quercetin-3'-sulphate $(\bullet)$ and quercetin-3-glucuronide $(\boldsymbol{\square})$; $(\mathrm{B})$, concentration of a quercetin glucuronide sulphate $(\bullet)$, isorhamnetin-3-glucuronide $(\boldsymbol{\square})$ and a quercetin diglucuronide $(\mathbf{\Lambda})$, in plasma from six human subjects collected $0-6 \mathrm{~h}$ after the ingestion of $270 \mathrm{~g}$ fried onions. For details of procedures, see p. 108. Values are means with their standard errors depicted by vertical bars $(n 6)$. Note that no quercetin metabolites were present in detectable amounts in plasma collected $24 \mathrm{~h}$ after supplementation.

which, arguably, is a consequence of the enhanced accuracy of analytical data obtained by HPLC-MS ${ }^{2}$.

Confirming the validity of the short $t_{1 / 2}$ values presented in Table 3, $92 \%$ of the urinary flavonol metabolites were excreted within the first $8 \mathrm{~h}$ after ingestion of onions (Table 4). Total $0-24 \mathrm{~h}$ flavonol metabolite excretion in urine for the individual subjects were 13.9, 13.7, 10.1, $16.4,9.6$ and $14.0 \mu \mathrm{mol}$ and the mean value of 12.9
(SE 1.1) $\mu \mathrm{mol}$ corresponds to $4.7 \%$ of intake. This is in agreement with the level of excretion of flavonols in urine after onion consumption by human subjects, reported by Graefe et al. (2001).

\section{Qualitative analysis of flavonol absorption}

The number and varieties of metabolites formed from the two main onion flavonols, quercetin-4'-glucoside and quercetin$3,4^{\prime}$-diglucoside, are shown in Table 1 . The present study provides no information on the mechanisms involved or the efficiency with which these compounds enter the enterocyte and are hydrolysed. However, it is evident that following release of the aglycone, quercetin is subjected to glucuronidation, sulphation and/or methylation. The enzymes involved in the synthesis of these metabolites from quercetin, glucuronosyltransferase, sulphotransferase and $O$-methyltransferase, have been found in human intestine (Radominska-Pandya et al. 1998; De Santi et al. 2000; Chen et al. 2003; Murota $\&$ Terao, 2003). It is, therefore, feasible that after the initial deglycosylation of the onion quercetin glucosides, all the quercetin metabolites that appear in plasma are the result of conversions occurring in the lumen of the small intestine. The reason for the individual metabolites displaying different pharmacokinetic profiles could be due to differing enzyme specificities and/or varying rates of efflux from the enterocyte into the bloodstream although deposition in body tissues and a slow release in the bloodstream could also be factors of influence.

Another possibility is that the major plasma metabolites, quercetin-3'-sulphate and quercetin-3-glucuronide, are produced in the small intestine, pass into the portal vein and are further converted to the more minor components, the quercetin glucuronide sulphate, the quercetin diglucuronide and isorhamnetin-3-glucuronide in the liver as illustrated in Figs. 4 and 5. Human hepatocytes contain glucuronyl-, sulphoand methyltransferases as well as $\beta$-glucuronidase activity (Boersma et al. 2002; O'Leary et al. 2003). Ex vivo incubation of quercetin-3-glucuronide with human hepG2 hepatonoma cells results in cleavage of the glucuronide moiety and the formation of quercetin-3'-sulphate (O'Leary et al. 2003). Further investigation is required to determine if this two-step pathway is the way in which the sulphate, the main quercetin plasma metabolite, is synthesised in vivo. A single-step sulphation of the aglycone in the enterocyte, as illustrated in Fig. 5,

Table 2. Pharmacokinetic parameters of quercetin metabolites in the plasma of six human subjects after the consumption of $270 \mathrm{~g}$ fried onions*

\begin{tabular}{|c|c|c|c|c|c|c|}
\hline \multirow[b]{2}{*}{ Metabolite } & \multirow[b]{2}{*}{ Peak number† } & \multicolumn{2}{|c|}{$C_{\max }(\mathrm{nm})$} & \multicolumn{2}{|c|}{$t_{\max }(\mathrm{h})$} & \multirow{2}{*}{$\begin{array}{c}t_{1 / 2}(\mathrm{~h}) \\
\text { Mean }\end{array}$} \\
\hline & & Mean & SE & Mean & SE & \\
\hline Quercetin-3'-sulphate & 22 & 665 & 82 & 0.75 & 0.12 & $1 \cdot 71$ \\
\hline Quercetin-3-glucuronide & 10 & 351 & 27 & 0.60 & 0.10 & $2 \cdot 33$ \\
\hline Isorhamnetin-3-glucuronide & 17 & 112 & 18 & 0.60 & $0 \cdot 10$ & $5 \cdot 34$ \\
\hline Quercetin diglucuronide & 9 & 62 & 12 & 0.80 & 0.12 & 1.76 \\
\hline Quercetin glucuronide sulphate & 14 & 123 & 26 & 2.5 & 0.22 & 4.54 \\
\hline
\end{tabular}

$C_{\max }$, maximum post-ingestion plasma concentration; $t_{\max }$, time to reach $C_{\max } ; t_{1 / 2}$, the elimination half-life of the metabolites.

${ }^{*}$ For details of procedures, see p. 108

†Peak numbers as in Fig. 2 and Table 1. 


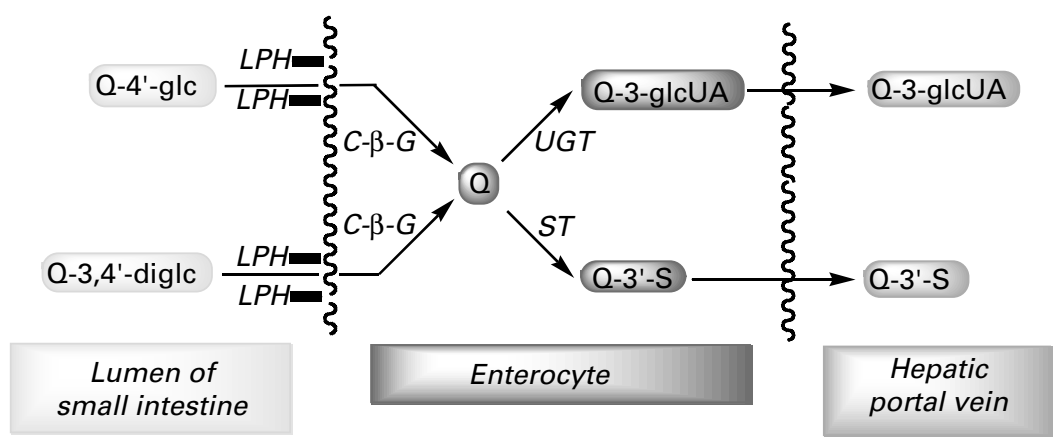

Fig. 4. Schematic of the proposed metabolic fate of quercetin- $4^{\prime}$-glucoside and quercetin- $3,4^{\prime}$-diglucoside as they pass from the lumen of the small intestine into the hepatic portal vein. C- $\beta-G$, cytosolic $\beta$-glucosidase; diglc, diglucoside; glc, glucoside; glcUA, glucuronide; Q, quercetin; LPH, lactase phlorizen hydrolase; $\mathrm{S}$, sulphate; ST, sulphotransferase; UGT, glucuronyltransferase.

would appear to be a more straightforward, but not necessarily exclusive, route.

The $C_{\max }$ values of plasma metabolites and $24 \mathrm{~h}$ urinary excretion of the flavonol metabolites (Table 4) detected after consumption of onions presents clear evidence of substantial phase II metabolism with many of the major urinary metabolites either not being detected in plasma or being present in low concentrations. For instance, quercetin- $3^{\prime}$-sulphate, the main plasma metabolite, was present in urine in only trace quantities while several quercetin glucoside glucuronides and quercetin glucoside sulphates, absent in plasma, were excreted in substantial amounts. The virtual absence of many of these urinary metabolites in plasma indicates that once released into the bloodstream they are rapidly removed by excretion via the kidneys. We assume that most of the observed metabolism occurs in the liver, which contains all the prerequisite enzymes, prior to transport to the kidneys. The exception, as illustrated in Fig. 5, may be the formation of the glucoside conjugates in the kidneys, which are known to possess $\beta$-glucosyltransferase activity (Matern \& Matern, 1987).

The data obtained with volunteer 6 was of interest in that quercetin, quercetin-3,4'-diglucoside and other flavonol glucosides were detected in plasma (Table 1). However, the levels were extremely low and these compounds were not detected in the plasma of the other five subjects. It has previously been reported that quercetin-4'-glucoside and isorhamnetin- $4^{\prime}$-glucoside appear in the bloodstream after ingestion of an onion meal by human volunteers (Aziz et al. 1998, 2003). These identifications were based on co-chromatography with authentic standards using a high resolution HPLC system with a post-column derivatisation procedure that produced fluorescent flavonol derivatives (Hollman et al. 1996). It has been suggested that the putative flavonol glucoside peaks were flavonol glucuronides which have very similar retention properties (Day \& Williamson, 2001). The present study with HPLC using $\mathrm{MS}^{2}$ detection indicates that this proposal is probably correct and that unmodified flavonol glucosides are not the main components to accumulate in plasma after the ingestion of onions. Similarly, reports on the occurrence of the disaccharide quercetin rutinoside in plasma (Paganga \& Rice-Evans, 1997; Mauri et al. 1999) are likely to be inaccurate.

The $4.7 \%$ recovery of the ingested flavonol glucosides as metabolites in urine leaves a large amount of the ingested dose unaccounted for. The most likely fate of these

Table 3. Concentration of quercetin metabolites $(\mathrm{nmol})$ in the urine of six human subjects $0-24 \mathrm{~h}$ after the consumption of $270 \mathrm{~g}$ fried onions* $^{*}$

\begin{tabular}{|c|c|c|c|c|c|c|c|c|c|}
\hline \multirow[b]{2}{*}{ Metabolites } & \multirow[b]{2}{*}{ Peak number† } & \multicolumn{2}{|c|}{$0-4 \mathrm{~h}$} & \multicolumn{2}{|c|}{$4-8 h$} & \multicolumn{2}{|c|}{$8-24 h$} & \multicolumn{2}{|c|}{ Total } \\
\hline & & Mean & SE & Mean & SE & Mean & SE & Mean & SE \\
\hline Quercetin-3-glucuronide & 10 & 512 & 101 & 400 & 113 & ND & & 912 & 149 \\
\hline Quercetin-3'-glucuronide & 19 & 979 & 220 & 804 & 194 & 62 & 30 & 1845 & 193 \\
\hline Quercetin diglucuronide & 9 & 1007 & 253 & 942 & 273 & 274 & 98 & 2223 & 417 \\
\hline Quercetin glucuronide glucoside & 3 & 99 & 21 & 64 & 16 & ND & & 163 & 23 \\
\hline Quercetin glucuronide sulphate & 13 & 608 & 124 & 566 & 143 & 210 & 73 & 1384 & 163 \\
\hline Quercetin glucuronide sulphate & 14 & 743 & 170 & 418 & 98 & 68 & 50 & 1229 & 190 \\
\hline Quercetin glucoside sulphate & 12 & 226 & 73 & 130 & 34 & 35 & 26 & 392 & 60 \\
\hline Quercetin glucoside sulphate & 15 & 538 & 127 & 257 & 98 & 26 & 11 & 821 & 156 \\
\hline Isorhamnetin-3-glucuronide & 17 & 767 & 18 & 861 & 9 & 161 & 6 & 1789 & 239 \\
\hline Isorhamnetin-4'-glucuronide & 20 & 451 & 11 & 249 & 2 & ND & & 700 & 114 \\
\hline Methylquercetin diglucuronide & 2 & 439 & 132 & 475 & 67 & 89 & 69 & 1003 & 156 \\
\hline Methylquercetin diglucuronide & 4 & 189 & 49 & 163 & 41 & 74 & 36 & 426 & 99 \\
\hline Total & & 6558 & 1323 & 5329 & 1018 & 999 & 267 & 12886 & 1038 \\
\hline
\end{tabular}

ND, not detected.

${ }^{\star}$ For details of procedures, see p. 108.

†Peak numbers as in Fig. 2 and Table 1. 
Table 4. Quercetin metabolites detected in plasma and urine of six human subjects after the consumption of $270 \mathrm{~g}$ fried onions ${ }^{*}$

\begin{tabular}{|c|c|c|c|c|c|}
\hline \multirow[b]{2}{*}{ Metabolite } & \multirow[b]{2}{*}{ Peak number† } & \multicolumn{2}{|c|}{ Plasmał } & \multicolumn{2}{|c|}{ Urine§ } \\
\hline & & Mean & SE & Mean & SE \\
\hline Quercetin diglucuronide & 1 & ND & & Trace\| & \\
\hline Methylquercetin diglucuronide & 2 & ND & & 1003 & 156 \\
\hline Quercetin glucoside glucuronide & 3 & ND & & 163 & 23 \\
\hline Methylquercetin diglucuronide & 4 & ND & & 426 & 99 \\
\hline Quercetin diglucuronide & 6 & ND & & Trace & \\
\hline Quercetin glucoside glucuronide & 7 & ND & & Trace & \\
\hline Quercetin glucoside glucuronide & 8 & ND & & Trace & \\
\hline Quercetin diglucuronide & 9 & 51 & 13 & 2223 & 417 \\
\hline Quercetin-3-glucuronide & 10 & 306 & 42 & 912 & 149 \\
\hline Quercetin glucoside sulphate & 12 & ND & & 393 & 60 \\
\hline Quercetin glucuronide sulphate & 13 & ND & & 1384 & 163 \\
\hline Quercetin glucuronide sulphate & 14 & 117 & 12 & 1229 & 190 \\
\hline Quercetin glucoside sulphate & 15 & ND & & 821 & 156 \\
\hline Isorhamnetin-3-glucuronide & 17 & 98 & 17 & 1789 & 27 \\
\hline Quercetin-4'-glucuronide & 18 & ND & & Trace & \\
\hline Quercetin-3'-glucuronide & 19 & Trace & & 1845 & 193 \\
\hline Isorhamnetin-4'-glucuronide & 20 & Trace & & 700 & 11 \\
\hline Quercetin-3'-sulphate & 22 & 539 & 46 & Trace & \\
\hline
\end{tabular}

ND, not detected

* For details of procedures, see p. 108

†Peak numbers refer to HPLC traces in Fig. 2 and Table 1.

¥ Estimates expressed as nM at peak plasma concentration.

$\S$ Amounts expressed as total amount excreted in nmol over a $24 \mathrm{~h}$ post-ingestion period.

II Trace: compound detected but not in sufficient amounts for routine quantification. Information on trace levels of metabolites detected exclusively in the plasma of volunteer 6 (see Table 1) are not presented.

compounds is that they are converted to low molecular weight phenolic acids (Depréz et al. 2000; Gonthier et al. 2003) most notably 3-hydroxyphenylpropionic acid, 3,4-dihydroxyphenylpropionic acid and 3-methoxy-4-hydroxyphenylpropionic acid (Olthof et al. 2003). These compounds were not analysed in the current study. They have a low extinction coefficient and a $\lambda_{\max }$ below $250 \mathrm{~nm}$ and as a result are not readily detected with a diode array detector and, in addition, they do not ionise readily when subjected to MS with an electrospray interface.

The data obtained in the present study reveal that extensive modification of quercetin glucosides occurs following ingestion of onions and the appearance of metabolites in the bloodstream and urine. The metabolic conversions involve a

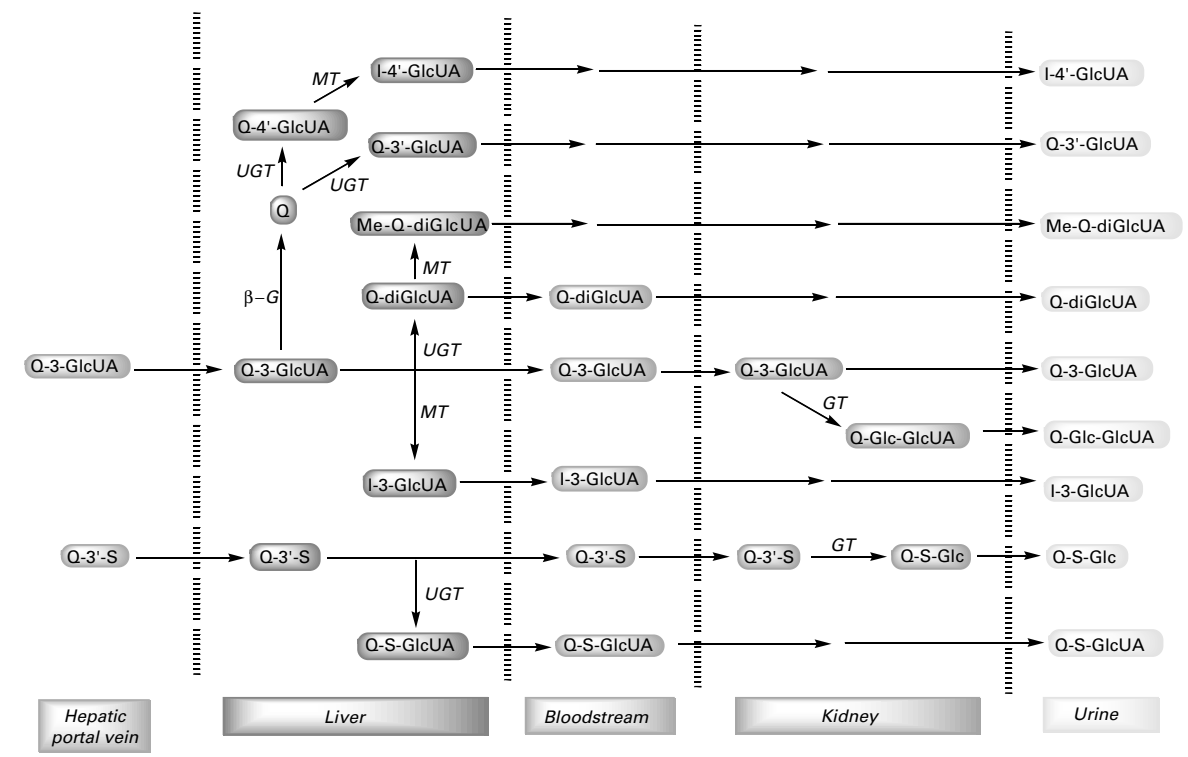

Fig. 5. Schematic of the proposed metabolic fate of quercetin-3-glucuronide and quercetin-3'-sulphate as they are transported from the small intestine to the liver where they are further metabolised before returning to the bloodstream and being excreted in urine via the kidneys. diglcUA, diglucuronide; $\beta$-G, $\beta$-glucosidase; glc, glucoside; glcUA, glucuronide; GT, glucosyltransferase; I, isorhamnetin; MT, methyltransferase; Q, quercetin; S, sulphate; UGT, glucuronyltransferase. 
complex combination of deglycosylation, glucuronidation, sulfation, methylation and possibly deglucuronidation steps. Where in the body these events take place and the sequence in which they occur after the initial deglycosylation, is a matter of speculation and a topic that requires further investigation. To this end, while experimentation with human subjects is useful it has it limitations as the deposition of flavonol metabolites in body tissues such as the liver, kidneys and brain is not possible for obvious reasons. Ex vivo studies with cultured cells and tissues have their place but it is open to doubt as to whether they reflect the true in vivo systems where the passage of metabolites into and out of cells and organs is likely to be subjected to refined controls. Animal test systems are, therefore, the only direct way in which the true bioavailability of flavonols and other dietary flavonoids and phenolics can be investigated. As demonstrated in recent studies with rats, this is best achieved using radiolabelled substrates as the accumulation of radioactivity in body fluids and tissues can be easily monitored by liquid scintillation counting and the compounds involved identified and quantified using HPLC $-\mathrm{MS}^{n}$ in combination with an on-line radioactivity monitor (Mullen et al. 2002, 2003).

There are several reasons why, in the present study, it was possible to obtain such a detailed insight into the fate of dietary quercetin glucosides following their ingestion. In the case of plasma samples, very clean extracts with high flavonol recoveries were obtained by using the extraction procedures of Day \& Williamson (2001). Secondly, an earlier investigation, in which $\left[2-{ }^{14} \mathrm{C}\right]$ quercetin- $4^{\prime}$-glucoside was ingested by rats and radiolabelled metabolites were monitored, alerted us to the possibility that quercetin glucosides may be converted in man to a much larger number of metabolites than had previously been anticipated (Mullen et al. 2002). In addition, recent improvements in the sensitivity of PDA detectors, in terms of flow cell optics with increased path lengths, have lowered limits of detection. Also, negative ion MS using ion trap $\mathrm{MS}^{n}$ has made it much easier to identify metabolite peaks observed in the improved absorbance traces.

\section{Conclusions}

The present study with human subjects, in which unhydrolysed extracts were analysed by HPLC with PDA and fullscan data-dependent $\mathrm{MS}^{n}$ detection, provided a far more detailed picture of the fate of flavonol glucosides within the body than was possible in earlier investigations. In total, twenty-three metabolites were either identified or partially identified with five being quantified in plasma and twelve in urine. If these samples had been subjected to hydrolysis only quercetin and isorhamnetin would have been detected and quantified. These data are of great importance in understanding the role of dietary flavonols in the prevention of chronic disease. The bioactivity of these metabolites must be studied to confirm the extent of their bioactivity and mechanisms of action.

\section{Acknowledgements}

The authors would like to thank the volunteers who participated in this study and also Drs Paul Needs and Paul Kroon,
Food Research Institute, Norwich, UK for generously supplying us with samples of quercetin metabolites. We would also like to thank Aurélie Boitier for her skilful assistance and Alison Sutcliffe who isolated quercetin-3-glucuronide from her home-grown French beans. The HPLC-MS ${ }^{2}$ system used in this study was purchased with a BBSRC grant to A. Crozier and J. R. Coggins.

\section{References}

Aziz AA, Edwards CA, Cahill AP, Khan KM, Finlay IG, Lean MEJ \& Crozier A (2003) Absorption and excretion of the conjugated flavonols, quercetin-3, $4^{\prime}$-diO- $\beta$-D-glucoside, quercetin- $4^{\prime}-O$ - $\beta$-D-glucoside and isorhamnetin- $4^{\prime}-O-\beta-\mathrm{D}$-glucoside, in human ileostomy volunteers after the consumption of onions. In Molecular and Therapeutic Aspects of Redox Biochemistry, pp. 194-205 [T Bahorun and A Gurib-Fakim, editors]. London: OICA International.

Aziz AA, Edwards CA, Lean MEJ \& Crozier A (1998) Absorption and excretion of conjugated flavonols, including quercetin- $4^{\prime}-O$ $\beta$-glucoside and isorhamnetin- $4^{\prime}-O$ - $\beta$-glucoside by human volunteers after the consumption of onions. Free Rad Res 29, 257-269.

Boersma MG, vad der Woude H, Bogaards J, Boerens S, Vervoort J, Cnubben NHP, van Iersel MLPS, van Bladeren PJ \& Tietjens IMCM (2002) Regioselectivity of phase II metabolism of luteolin and quercetin by UDP-glucuronyl transferases. Chem Res Toxicol 15, 662-670.

Caldwell ST, Crozier A \& Hartley RC (2000) Isotopic labelling of quercetin-4'-O- $\beta$-glucoside. Tetrahedron 56, 4101-4106.

Chen G, Zhang D, Jing N, Yin S, Falany CN \& Radominska-Pandya A (2003) Human intestinal sulfotransferases: identification and distribution. Toxicol Appl Pharmacol 187, 186-197.

Crozier A, Lean MEJ, McDonald MS \& Black C (1998) Quantitative analysis of the flavonoid content of commercial tomatoes, onions, lettuce and celery. J Agric Food Chem 45, 590-595.

Crozier A, Yokota T, Jaganath IB, Marks S, Saltmarsh M \& Clifford MN (2006) Secondary metabolites in fruits, vegetables and other plant-derived dietary components. In Plant Secondary Metabolites: Occurrence, Structure and Role in the Human Diet [A Crozier, $\mathrm{H}$ Ashihara and MN Clifford, editors]. Oxford: Blackwells, (In the Press).

Day AJ, Gee JM, DuPont MS, Johnson IT \& Williamson G (2003) Absorption of quercetin-3-glucoside and quercetin- $4^{\prime}$-glucoside in the rat small intestine: the role of lactase phloridzin hydrolase and sodium-dependent glucose transporter. Biochem Pharmacol 65, 1199-1206.

Day AJ, Mellon F, Barron D, Sarrazin G, Morgan MRA \& Williamson G (2001) Human metabolism of dietary flavonoids: identification of plasma metabolites of quercetin. Free Rad Res 35, $941-952$.

Day AJ \& Williamson G (2001) Biomarkers of dietary flavonoids: a review of the current evidence for identification of quercetin glycosides in plasma. Br J Nutr 86, S105-S110.

Day AJ \& Williamson G (2003) Absorption of quercetin glycosides. In Flavonoids in Health and Disease, pp. 391-412 [CA RiceEvans and L Packer, editors]. New York: Marcel Dekker.

Déprez S, Brezillon C, Rabot S, Philippe C, Mila I, Lapierre C \& Scalbert A (2000) Polymeric proanthocyanidins are catabolized by human colonic microflora into low-molecular-weight phenolic acids. J Nutr 130, 2733-2738.

De Santi C, Pietrabissa A, Spisni R, Mosca F \& Pacifici GM (2000) Sulphation of reseveratrol, a natural product present in grapes and wine, in human liver and duodenum. Xenobiotica 30, 609-617.

Gonthier M-P, Donovan JL, Texier O, Felgines C, Rémésy C \& Scalbert A (2003) Metabolism of dietary procyanidins in rats. Free Rad Biol Med 35, 837-844. 
Graefe EU, Wittig J, Mueller S, Riethling A-K, Uehleke B, Drewelow B, Pforte H, Jacobasch G, Derendorf H \& Veit M (2001) Pharmacokinetics and bioavailability of quercetin glycosides in humans. J Clin Pharmacol 41, 492-499.

Hollman PCH, van der Gaag MS, Mengelers MJB, van Trijp JMP, de Vries JHM \& Katan MB (1996) Absorption and disposition kinetics of the dietary antioxidant quercetin in man. Free Rad Biol Med 21, 703-707.

Hollman PCH, van Trip JMP, Buysman MNCP, van der Gaag MS, Mengelers MJB, de Vries JHM \& Katan MB (1997) Relative bioavailability of the antioxidant quercetin from various foods. FEBS Lett 418, 152-156.

Matern H \& Matern S (1987) Formation of bile acid glucosides and dilichyl phosphoglucose by microsomal glucosyl transferases in liver, kidney and intestine of man. Biochim Biophys Acta 921, 1-6.

Mauri PL, Iemoli L, Gardana C, Riso P, Simonetti P, Porrini M \& Pietta PG (1999) Liquid chromatography electrospray ionization mass spectrometric characterization of flavonol glycosides in tomatoes extracts and human plasma. Rapid Commun Mass Spectrom 13, 924-931.

Moon J-H, Makata R, Oshima S, Inakuma T \& Terao J (2000) Accumulation of quercetin conjugates in blood plasma after the short-term ingestion of onions by women. Am J Regulatory Integrative Comp Physiol 279, R461-R467.

Mullen W, Boitier A, Stewart AJ \& Crozier A (2004) Flavonoid metabolites in human plasma and urine after the consumption of red onions: analysis by liquid chromatography with photodiode array and full scan tandem mass spectrometric detection. J Chromatogr A 1058, 163-168.

Mullen W, Graf BA, Caldwell ST, Hartley RC, Duthie GG, Lean MEJ \& Crozier A (2002) Determination of flavonol metabolites in plasma and tissues of rats by HPLC-radiocounting and tandem mass spectrometry following oral ingestion of $\left[2{ }^{14} \mathrm{C}\right]$ quercetin4'-glucoside. J Agric Food Chem 50, 6902-6909.

Mullen W, Hartley RC \& Crozier A (2003) Detection and identification of ${ }^{14} \mathrm{C}$-labelled flavonol metabolites by HPLC-radio-counting and tandem mass spectrometry. J Chromatogr A 1007, 21-29.

Murota K \& Terao J (2003) Antioxidative flavonoid quercetin: implication of its intestinal absorption and metabolism. Arch Biochem Biophys 417, 12-17.

O'Leary KA, Day AJ, Needs PW, Mellon FA, O'Brien NM \& Williamson G (2003) Metabolism of quercetin-7- and quercetin3-glucuronides by an in vitro hepatic model: the role of human $\beta$-glucuronidase, sulfotransferase, catechol- $O$-methyltransferase and multi-resistant protein 2 (MRP2) in flavonoid metabolism. Biochem Pharmacol 65, 479-491.

Olthof MR, Hollman PCH, Buijsman MNCP, Amelsvoort JMM \& Katan MB (2003) Chlorogenic acid, quercetin-3-rutinoside and black tea polyphenols are extensively metabolized in humans. J Nutr 133, 1806-1814.

Paganga G \& Rice-Evans CA (1997) The identification of flavonoids as glycosides in human plasma. FEBS Lett 401, 78-82.

Radominska-Pandya A, Little JM, Pandya JT, Tephly TR, King CD, Barone GW \& Raufman J-P (1998) UDP-glucuronyltransferases in human intestinal mucosa. Bichim Biophys Acta 1394, 199-208.

Tsushida T \& Suzuki M (1995) Isolation of flavonoid-glycosides in onion and identification by chemical synthesis of the glycoside (Flavonoids in fruits and vegetables. Part I). Nippon Shokuhin Kagaku Kaishi 42, 100-108.

Wittig J, Herderich M, Graefe EU \& Veit M (2001) Identification of quercetin glucuronides in human plasma by high-performance liquid chromatography-tandem mass spectrometry. J Chromatogr B 753, 237-243. 